\title{
Gerenciamento dos resíduos de serviços de saúde: considerações a partir da atuação do profissional farmacêutico
}

\section{Wandson do Nascimento Silva ${ }^{1}$ e Cassiano Augusto Oliveira da Silva ${ }^{2}$}

\author{
${ }^{1}$ Universidade Federal do Ceará. Programa de Pós-Graduação em Geografia. \\ Campus do Pici, Bloco 902. Fortaleza-CE, Brasil (CEP 60440-554). \\ E-mail: wandsongba@hotmail.com. \\ ${ }^{2}$ Secretaria de Estado da Saúde da Paraíba. Comissão Estadual de Controle de \\ Infecção em Serviços de Saúde. Av. Dom Pedro II, 1826. Torre. João Pessoa-PB, \\ Brasil (CEP 58040-903).
}

Resumo. A sociedade enfrenta diariamente sérios problemas que afetam na qualidade da vida humana e na preservação do meio ambiente. Pensar em práticas sustentáveis tem sido o grande desafio do poder público como também das populações. Neste sentido, discutir o gerenciamento dos resíduos provenientes dos serviços de saúde, a partir de pontos de vistas diferentes, torna-se importante para a compreensão do atual cenário que se insere os resíduos de serviços de saúde. Partindo dessa premissa, o presente trabalho tem por objetivo realizar uma abordagem a partir da visão do profissional farmacêutico no processo de gerenciamento dos resíduos de serviços de saúde. Para isso se fez necessário o uso de uma metodologia exploratória descritiva, a partir de levantamentos bibliográficos e documental. Desta forma considera-se que se tratando do gerenciamento dos resíduos de saúde, o farmacêutico desempenha importante papel, uma vez que detém o conhecimento técnico em relação a patologias, manuseio de substâncias e cumprimento das legislações vigentes.

Palavras-chave: Resíduos de serviços de saúde; Resíduos perigosos; Gerenciamento de resíduos; Farmacêutico.

Abstract. Waste management of healthcare services: Considerations from the performance of the pharmaceutical professional. Society daily faces serious problems affecting the quality of human life and the preservation of the environment. Thinking about sustainable practices has been the great challenge of the public authorities as well as of the people. In this regard, discussing the management of waste from health services, from different points of view, becomes important for understanding the current scenario that is part of the healthcare waste. Based on this premise, the present study aims to achieve an approach based on the pharmaceutical professional's vision in the waste management process of health services. For this it was necessary

Recebido 25/07/2019

Aceito

26/12/2019

Publicado

31/12/2019

Acesso aberto

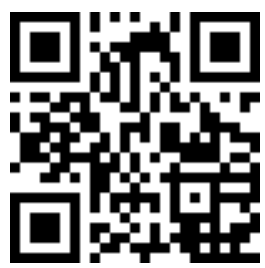

ORCID

(D) 0000-0001-9300-979X

Wandson do

Nascimento Silva

D 0000-0002-8461-9104

Cassiano Augusto

Oliveira da Silva 
to use an exploratory descriptive methodology, based on bibliographic and documentary surveys. In this way, it is considered that when it comes to the management of health residues, the pharmacist plays an important role, since it holds the technical knowledge in relation to pathologies, substance handling and compliance with existing legislation.

Keywords: Medical waste; Hazardous waste; Waste management; Pharmaceutist.

\section{Introdução}

Um manejo inadequado de resíduos sólidos produz desperdício, corrobora expressivamente com à manutenção das desigualdades sociais, institui-se uma ameaça constante à saúde pública, agrava a degradação do meio ambiente e de seus recursos e afeta de forma danosa a qualidade de vida dos seres vivos. (SUDEMA, 2004, p. 13)

Um dos fatores motivadores desta pesquisa que aborda a temática dos Resíduos de Serviço de Saúde (RSS), comumente conhecido como lixo hospitalar, foi o impacto causado por estes resíduos dentro do ambiente profissional, bem como consequências para o meio ambiente, o que vem ressaltar e expor a falta de um manejo adequado e de um eficaz gerenciamento dos RSS.

A atenção aos RSS, no Brasil, veio ganhar ênfase no início da década de 1990, entretanto, neste período a questão dos resíduos sólidos não estava regulamentada pelo Ministério do Meio Ambiente, que só evidenciou esforços no sentido de regulamentá-los no inicio do ano de 2005 (Brasil, 2006, p.17)

Atualmente o Brasil possui um arcabouço legal evoluído e vasto principalmente no que se refere às leis de proteção ambiental, esse amparo legal poderá ser observado no decorrer de toda esta pesquisa, pois objetivamos expor as leis que regem o Gerenciamento de Resíduos de Serviço de Saúde (GRSS) no Brasil, sua trajetória histórica e a atuação do farmacêutico no GRSS.

\section{Metodologia}

O rumo metodológico tomado por nós para a elaboração deste artigo cientifico foi a pesquisa bibliográfica, e como estratégia de ação realizamos pesquisas nos acervos de instituições de ensino, de órgãos públicos e da rede mundial de computadores, sendo esta última excelente fonte de acesso na verificação das leis que regem a República Federativa do Brasil. Desta forma a pesquisa apresenta-se de cunho qualitativo, pois estamos abordando o conhecimento referente ao universo das leis ambientais do Brasil e mais precisamente as leis que conduzem o GRSS.

O conhecimento legal para a atuação profissional é um tipo de saber que não pode ser mensurado, porem cabe ao profissional dominá-lo. Conhecer a lei acaba por se tornar uma obrigação, pois, como rege o art. 3ํㅡㄹ do Decreto-Lei no 4.657/1942, "ninguém se escusa de cumprir a lei, alegando que não a conhece" (Brasil, 1942).

A abundância de leis ambientais no Brasil é do conhecimento de muitos, pois se trata de um fato decorrente de trajetória histórica do nosso país, desde o momento em que nos tornamos colônia de Portugal, através do "descobrimento", até a contemporaneidade.

Ao tempo em que o Brasil foi descoberto, vigoravam em Portugal as Ordenações Afonsinas, primeiro Código legal europeu, cujo trabalho de compilação foi concluído no ano de 1446. Podemos afirma que a legislação ambiental portuguesa era 
extremamente evoluída. 0 corte deliberado de árvores frutíferas foi proibido através da ordenação determinada pelo rei D. Afonso IV, em 12 de março de 1393, tendo sido posteriormente compilada [...] nas Ordenações Afonsinas.

Interessante notar que a lei ordenada por D. Afonso IV, tipifica o corte de árvores de fruto como crime de injúria ao rei, tamanha a preocupação com a proteção florestal.

Em relação aos animais, a preocupação com as aves era ainda mais antiga, [...] onde equiparava o furto das aves para efeitos criminais a qualquer outra espécie de furto. (Wainer, 1999, p. 4-5).

A primeira lei protecionista florestal do Brasil data de 12 de dezembro de 1605, era o "Regimento sobre o pau-brasil", posteriormente foram sendo editadas leis, normas e notas que englobavam a temática ambiental.

Durante o período do domínio holandês na região nordeste do Brasil (1624-1654), nossa história também experimentou da evoluída legislação ambiental holandesa.

No Brasil, os holandeses foram obrigados a editar leis ambientais que determinavam desde a proibição do corte de árvores, ao cuidado com a poluição das águas, no caso da pesca, é

[...] interessante o especial cuidado que obteve das autoridades holandesas, estendido que foi à caça e à passarinhagem, conforme pode verificar através do parágrafo 19 da 'Acta de 13.10.1629', em que as três atividades eram permitidas desde que as diversa espécies de caça não fossem 'exterminadas' por uma perseguição excessiva; além do que, apoiaram a conservação das espécies já existentes, determinando a introdução daquelas que ainda não havia na região e que nela podiam ser aclimatadas (Wainer, 1999, p. 27).
Ao longo dos séculos, as questões jurídicas no Brasil sofreram transformações e adaptações com o surgimento de novas leis, decretos, leis de concessões publicas entre outras inúmeras normas.

No ano de 1870, dezenove anos antes da Proclamação da República do Brasil, sua alteza imperial Dom Pedro II concede ao senhor Aleixo Gary o serviço de coleta e destinação dos resíduos sólidos gerados na capital do império, desta época até o inicio da década de cinqüenta do século $\mathrm{XX}$ a preocupação com o manejo dos resíduos sólidos destinava-se basicamente na coleta e sua disposição era realizada em qualquer lugar, o importante era sair da vista da população (Brasília, 2003, p. 32).

No quesito saúde é promulgado o Decreto de no 16.300/1923, "que dispôs sobre a saúde e saneamento, importante passo foi dado em favor do controle da poluição, quando se proibiu instalações de indústrias nocivas e prejudiciais à saúde de residências vizinhas" (Wainer, 1999, p. 58).

No Decreto no $16.300 / 1923$ (Brasil, 1923) é interessante observar o texto do art. 108, "que visava a promover as noções de higiene pessoal e pública [...]." (Wainer, 1999, p. 58). Apesar de todo esse aparato legal não podemos esquecer que a proteção do meio ambiente não foi um objetivo a ser percorrido e sim inicialmente uma questão de manutenção de subsistência e mais tarde de ordenamento urbano.

Antes da Constituição Federal de 1988 não havia textos constitucionais relacionados à temática ambiental, portanto, é mister citar o caput do seu art. 225 , onde diz que:

Art. 225. Todos têm direito ao meio ambiente ecologicamente equilibrado, bem de uso comum do povo e essencial à sadia qualidade de vida, impondo-se ao poder público e à coletividade o dever de defendê-lo e preservá-lo para as presentes e futuras gerações (Brasil, 1988). 
Constituição:

Com a promulgação desta

0 direito ao meio ambiente ecologicamente equilibrado passou a ser, [...], um direito fundamental de todos os brasileiros e do todas as pessoas que estiverem no Brasil. Por ser direito fundamental, é um direito indisponível, do qual não se pode abrir mão (Nalini, 2003, p. 290).

Sobre a proteção do meio ambiente e de seus recursos, a Constituição Federal de 1988, enumerou os deveres que estão sob a égide do poder público. Desta forma, coube proteger e restaurar os processos ecológicos essenciais. 0 texto constitucional versa que:

Art. 225.

§ 1ํ Para assegurar a efetividade desse direito, incumbe ao poder público:

I - preservar e restaurar os processos ecológicos essenciais e prover o manejo ecológico das espécies e ecossistemas;

II - preservar a diversidade e a integridade do patrimônio genético do País e fiscalizar as entidades dedicadas à pesquisa e manipulação de material genético;

[...]

IV - exigir, na forma da lei, para instalação de obra ou atividade potencialmente causadora de significativa degradação do meio ambiente, estudo prévio de impacto ambiental, a que se dará publicidade. V-controlar a produção, a comercialização e o emprego de técnicas métodos e substancias que comportem risco para a vida, a qualidade de vida e o meio ambiente (Brasil, 1988).

Compondo à defesa expressa pelo texto da Constituição de 1988, tem-se a legislação inferior.

A Lei no 9.605/1998 (Lei de Crimes Ambientais) determina que:
Art. 54. Causar poluição de qualquer natureza em níveis tais que resultem ou possam resultar em danos à saúde humana, ou que provoquem a mortandade de animais ou a destruição significativa da flora:

Pena - reclusão, de um a quatro anos e multa.

[...]

$\S 2^{\circ}$ Se o crime:

[...]

V - ocorrer por lançamentos de resíduos sólidos, líquidos ou gasosos, ou detritos, óleos ou substâncias oleosas, em desacordo com as exigências estabelecidas em leis ou regulamentos:

Pena - reclusão, de um a cinco anos.

\section{[...]}

Art. 56. Produzir, processar, embalar, importar, exportar, comercializar, fornecer, transportar, armazenar, guardar, ter em depósito ou usar produto ou substancias tóxica, perigosa ou nociva à saúde humana ou ao meio ambiente, em desacordo com as exigências estabelecidas em lei ou nos seus regulamentos:

Pena - reclusão, de um a quatro anos e multa.

\section{[...]}

$\S 2^{\circ}$ Se o produto ou a substância for nuclear ou radioativa, a pena é aumentada de um sexto a um terço.

\section{[...]}

Art. 60. Construir, reformar, ampliar, instalar ou fazer funcionar, em qualquer parte do território nacional, estabelecimento, obras ou serviços potencialmente poluidores, sem licença ou autorização dos órgãos ambientais competente, ou contrariando as normas legais e regulamentares pertinentes:

Pena - detenção, de um a seis meses ou multa, ou ambas as penas cumulativas. 
Art. 61. Disseminar doença ou praga ou espécies que possam causar dano à agricultura, à pecuária, à fauna, à flora ou aos ecossistemas:

Pena - reclusão, de um a quatro anos, e multa (Brasil, 1998).

Saindo desta esfera mais ampla e atual da Constituição Federal de nossa República e partindo para um entendimento mais especifico no que se refere a legislação direcionada aos RSS, é interessante realizarmos um pequeno retorno na história, mais precisamente no ano de 1979, quando o Ministério do Interior (MINTER), órgão hoje extinto, promulga a Portaria $\mathrm{n}$ - 53/1979 que determinava a incineração de todos os resíduos gerados pelos serviços de saúde (Brasil, 1979).

Com essa determinação de incineração, podemos observar que houve a falta de um conhecimento característico relacionado às questões químicas, biológicas, radiológicas, físicas, mecânica e operacional. Nesta portaria, a proteção do meio ambiente e do trabalhador foram temáticas que ficaram de fora.

Após 12 anos de vigência da Portaria MINTER no 53/1979, o Conselho Nacional de Meio Ambiente (CONAMA) publica a Resolução CONAMA no 06/1991, que desobriga qualquer tipo de incineração. Vejamos o artigo primeiro da mesma, onde determina que:

Art. 1ํ Fica desobrigada a incineração ou qualquer outro tratamento de queima dos resíduos sólidos provenientes dos estabelecimentos de saúde, portos e aeroportos, ressalvados os casos previstos em lei e acordos internacionais (Brasil, 1991).

Esta determinação de incinerar os resíduos sólidos provenientes dos de saúde, portos e aeroportos foi de fundamental importância, pois de certa forma serviu para conter mais uma fonte de poluição, gerada pela incineração dos resíduos sólidos oriundos dos estabelecimentos de saúde, portos e aeroportos. Com esta resolução, os RSS conquistam uma projeção legal dentro do Brasil.

0 ano de 1993 é marcado pela criação, por meio de transformação do Ministério do Meio Ambiente e da Amazônia Legal, pela Lei no 8.746/1993, órgão que vem para representar a posição do governo a respeito das questões ambientais e do patrimônio natural do país.

Ainda no ano de 1993, foi publicada a Resolução CONAMA no 5/1993, que é conhecida como a primeira resolução que irá versar especificamente sobre os RSS, trazendo as definições de resíduos sólidos, do plano de gerenciamento de resíduos sólidos, do sistema de tratamento de resíduos sólidos, bem como do sistema de disposição final de resíduos sólidos.

Além dessas definições, ela vem nos trazer as classificações de tais resíduos por meio de grupos, vejamos como esses são classificados:

GRUPO A: resíduos que apresentam risco potencial à saúde pública e ao meio ambiente devido a presença de agentes biológicos.

GRUPO B: resíduos que apresentam risco potencial à saúde pública e ao meio ambiente devido às suas características químicas.

GRUPO C: rejeitos radioativos.

GRUPO D: resíduos comuns são todos os demais que não se enquadram nos grupos descritos anteriormente (Brasil, 1993).

Ao final o século $X X$, define-se o Sistema Nacional de Vigilância Sanitária e cria-se a Agência Nacional de Vigilância Sanitária (ANVISA), por meio da Lei $\mathrm{n}^{\mathrm{o}}$ 9.782/1999.

Desta forma, a ANVISA tem por desígnio institucional:

[...] promover a proteção da saúde da população, por intermédio do controle sanitário da produção e da 
comercialização de produtos e serviços submetidos à vigilância sanitária, inclusive dos ambientes, dos processos, dos insumos e das tecnologias a eles relacionados, bem como o controle de portos, aeroportos e de fronteiras (ANVISA, 1999).

No início do terceiro milênio, o CONAMA institui a Resolução $\mathrm{n}^{\underline{0}}$ 283/2001, vindo dispor sobre o tratamento e a destinação final dos RSS. Fazendo uma analise do texto desta lei, podemos observar que as definições abordadas pela Resolução CONAMA no 5/1993 ficaram sendo mantidas, enquanto outros assuntos foram revogados.

Em 2004, a ANVISA vem a aprimorar os questionamentos legais que se referem aos RSS, com a Resolução de Diretoria Colegiada (RDC) no 306/2004. Esta RDC vem considerar princípios que para o momento são peças fundamentais nos temas relacionados ao meio ambiente, como é o caso da biossegurança, do uso de novas medidas técnicas que tem como fim primordial a preservação da saúde humana e do meio ambiente. Assim como, também, traz a regulamentação para o GRSS, a RDC nº 306/2004 dispõe sobre o regulamento técnico para o gerenciamento de resíduos de serviços de saúde.

O CONAMA no ano de 2005 publica mais uma resolução, a Resolução no 358/2005, onde dispõe sobre o tratamento e a disposição final dos RSS além de fornecer outras providências. Essa resolução foi publicada para eliminar alguns conflitos que foram posteriormente observados na RDC ANVISA nº 306/2004 e na Resolução CONAMA no 358/2005, vindo ser aplicada em todos os serviços relacionados com o atendimento à saúde humana ou animal (Brasil, 2005).

Com a Resolução CONAMA no 358/2005 a classificação dos resíduos sólidos ganhou em seus grupos novos elementos e uma vasta atualização, isto pode ser visto no anexo I desta resolução, já o anexo II nos apresenta os critérios mínimos para a disposição final dos RSS exclusivamente.

A RDC ANVISA no 306/2004 e a Resolução CONAMA no 358/2005, expõe um conhecimento cientifico mais aprofundado nos apresentando quem são os geradores de resíduos sólidos de saúde e abordando sobre a disposição final desses resíduos de maneira mui ajuizada, isso por trabalhar com todos os rejeitos e materiais do cotidiano dos serviços de saúde. Tal aspecto demonstra uma preocupação com os materiais que por um manuseio ou armazenamento inadequado poderiam causar graves danos a vida, quer seja humana ou não.

Por sua vez, a ANVISA, em 28 de março de 2018, publica a RDC no $222 / 2018$ que vem a preencher algumas lacunas referentes a questionamentos surgidos a partir da RDC ANVISA no 306/2004 e da Resolução CONAMA no $358 / 2005$, como também da Lei $\mathrm{n}^{0}$ 12.305/2010 (Brasil, 2010). Com isto, esta nova resolução tem como objetivo realizar uma abordagem sobre as boas práticas de gerenciamento dos RSS, de forma a minimizar os riscos referentes à saúde humana, animal, proteção do meio ambiente e recursos naturais, que ainda necessitavam de um melhor refinamento do tema.

Além da legislação específica dos RSS, também há as normas da Associação Brasileira de Normas Técnicas (ABNT), como as normas ABNT NBR no 12807:1993, referindo-se as terminologias dos resíduos de serviços de saúde, a ABNT NBR no 12808:1993, a qual se refere a classificação de tais resíduos, a ABNT NBR no 12809:1993, que aborda os procedimentos a serem tomados para o manuseio de RSS, bem como a ABNT NBR no 12810:1993, que versa sobre os procedimentos para a coleta dos resíduos de serviço de saúde, estas por sua vez, tem como fundamento e eixo norteador a legislação brasileira (ABNT, 1993). 
Quando falamos em leis, é significante compreendermos que a União exerce um papel normativo e os estados e municípios complementam com as leis locais, já que conhecem e atuam dentro das singularidades e especificidades de cada região.

Os RSS aparecem, dentro de um cenário de transformações e agravamento das questões ambientais, como um dos grandes agressores do meio ambiente e da saúde humana.

Esta situação coloca os RSS em um lugar de destaque, merecendo, por sua vez, atenção especial em todas as suas fases de manejo (segregação, acondicionamento, armazenamento, coleta, transporte, tratamento e disposição final) em decorrência dos imediatos e graves riscos que podem oferecer, por apresentarem componentes químicos, biológicos e radioativos (Brasil, 2006, p. 30).

A RDC ANVISA no 306/2004 dispõe, como já mencionamos, sobre o regulamento técnico para o GRSS, e no seu anexo traz as diretrizes gerais do regulamento técnico para o GRSS.

A respeito deste anexo, mais precisamente no capítulo 3으, observamos o GRSS como sendo:

[...] um conjunto de procedimentos de gestão, planejados e implementados a partir de bases científicas e técnicas, normativas e legais, com o objetivo de minimizar a produção de resíduos e proporcionar aos resíduos gerados, um encaminhamento seguro, de forma eficiente, visando à proteção dos trabalhadores, a preservação da saúde pública, dos recursos naturais e do meio ambiente (ANVISA, 2004).

Daí todos geradores de resíduos, e a classificação desses geradores são observados no capítulo $2^{\mathrm{o}}$ da mesma, devem preparar um Plano de Gerenciamento de Resíduos de Serviços de Saúde (PGRSS), com o objetivo de constituir as diretrizes de manejo dos RSS.
A determinação estabelecida no capitulo $3^{0}$ é que o PGRSS seja compatível com as normas locais relativas à coleta, transporte e disposição final dos resíduos gerados nos serviços de saúde, estabelecidas pelos órgãos locais responsáveis pelas etapas de manejo, segregação, acondicionamento, identificação, transporte interno, armazenamento temporário, tratamento, armazenamento externo, coleta e transportes externos e disposição final (ANVISA, 2004).

Depois de conhecermos a lei que regulamenta o GRSS, faz-se necessário, compreendermos o que são os resíduos do serviço de saúde. O que antes se conhecia como lixo hospitalar, hoje segundo a ABNT é denominado RSS, e são provenientes não apenas de hospitais, mas também de ambulatórios, consultórios médicos e odontológicos, clínicas veterinárias, farmácias laboratórios de análises clínicas e patológicas, bancos de sangue ou leite, além de estações rodoferroviarias, portos e aeroportos e locais de grande afluxo de pessoas (Takayanagui, 2005, p. 324-325).

No GRSS dois momentos são de fundamental importância $o$ primeiro deles é a segregação que permite uma redução na geração de resíduos infectantes e/ou com risco biológico, por meio da não contaminação do resíduo comum com este, possibilita a adoção de procedimentos para o manejo de cada grupo de resíduos, permite o tratamento específico, para cada categoria de resíduos, diminui os custos no manejo dos resíduos, reaproveita ou reutiliza parte dos resíduos do grupo $\mathrm{D}$, reduz o risco para a saúde e por conseqüência otimiza a qualidade de vida dos trabalhadores que estão intimamente envolvidos no manejo de tais resíduos. Outro momento importante do gerenciamento é o acondicionamento que funciona como mecanismo de proteção, minimizando e até mesmo impedindo o risco de contaminação.

Tomando conhecimento da forma como se deve proceder o manejo dos RSS 
no que se refere a fase de acondicionamento, pois esta fase é de fundamental importância no que se refere ao conhecimento do farmacêutico no GRSS, é interessante retomarmos as orientações da RDC ANVISA no 306/2004 e as normas da associação brasileira de normas técnicas.

Os resíduos do Grupo A deverão ser acondicionados em sacos plásticos de cor branco leitoso, resistente, impermeável e identificado com rotulo de fundo branco, desenho e contorno preto, contendo o símbolo universal de substância infectante e a inscrição "Risco Biológico" ou "infectante" como determina a ABNT NBR 7500:2007, sendo substituído quando atingir $2 / 3$ de sua capacidade ou pelo menos uma vez a cada 24 horas. Havendo a perda das características física das estruturas pode ser acondicionados com os resíduos do Grupo D.

Os resíduos do Grupo A1 com suspeita de contaminação biológica deverão ser acondicionados em sacos de cor vermelha sendo substituído quando atingir $2 / 3$ de sua capacidade ou pelo menos uma vez a cada 24 horas. E caso haja a descaracterização a perda das características física das estruturas podem ser acondicionados com os resíduos do Grupo D.

Aos resíduos do Grupo A2 o acondicionamento deverá ser realizado em saco branco leitoso, resistente a ruptura e vazamento, impermeável, baseado na norma ABNT NBR 9191:2000 (ABNT, 2000) e substitutivas, respeitados os limites de peso de cada saco sendo substituído quando atingir $2 / 3$ de sua capacidade ou pelo menos uma vez a cada 24 horas.

Para os resíduos do Grupo A3 e A4 seguido o registro no local de geração estes deverão ser acondicionados em saco branco leitoso resistente a ruptura e vazamento, impermeável, baseado na norma ANNT NBR 9191:2000 (ABNT, 2000) sendo substituído quando atingir $2 / 3$ de sua capacidade, sendo proibido o seu esvaziamento ou reaproveitamento.
Nos casos de peças anatômicas encaminhadas para incineração estas deverão ser acondicionada em sacos de cor vermelha e identificada.

A respeito dos resíduos do grupo A5 devem ser acondicionados em sacos de cor vermelha, que devem ser substituídos após cada procedimento e identificados, substituídos após cada procedimento e devem ser usados dois sacos como barreira de proteção, com preenchimento $2 / 3$ de sua capacidade, ficando proibido o seu esvaziamento ou reaproveitamento.

Os resíduos do grupo B terão seu acondicionamento em sacos plásticos de cor branco leitoso, resistente, impermeável identificado com rótulo de fundo branco, desenho e contorno preto, contendo o símbolo universal de substância tóxica e a inscrição correspondente de risco químico. É interessante a utilização de sacos duplos tendo em vista a quantidade de resíduos produzidos e o grau de umidade dos mesmos. Sua segregação e seu acondicionamento deverão ser realizados de forma isolada observando a relação entre a embalagem e a natureza química do resíduo a ser gerido.

Se os resíduos do grupo B produzidos forem de natureza física líquida estes deverão ser acondicionados em depósito apropriado e com capacidade de resistência para a natureza química e para o estado físico deste tipo de resíduo. Caso os resíduos do grupo B sejam gerados pelos serviços ou por programas de assistência domiciliar, estes deverão ser geridos pelo profissional prestador do atendimento ou por pessoas capacitadas e habilitadas que saberá encaminhar de forma correta e segura para o local referenciado. Os resíduos do grupo $\mathrm{C}$ expõem os seres vivos e o meio natural a uma condição maior de perigo, por envolver os rejeitos radiativos. Estes tipos de resíduo devem seguir as orientações da Comissão Nacional de Energia Nuclear (CNEN).

A segregação de resíduos do grupo $\mathrm{C}$ seguirá em conformidade com a 
Resolução CNEN no 194/2016 (Brasil, 2016), respeitando a natureza física do material e do radionuclídeo e o tempo necessário para atingir o limite de eliminação. Seu acondicionamento deverá ser em recipientes de plástico de até dois litros ou em bombonas de material rígido, resistente, compatível com o líquido armazenado e estanques com tampa rosqueada, vedante, acomodados em bandejas de material inquebrável e com profundidade. É a identificação com o símbolo internacional de substância radioativa (Brasil, 1985).

A respeito do armazenamento dos resíduos do grupo $\mathrm{C}$ será realizado no próprio local da geração ou em local com acesso restrito que apresente segurança, devendo ser observado o sistema de blindagem no deposito ou no local de armazenamento. Por sua vez, os resíduos do grupo D possuem as mesmas características dos resíduos domésticos, por esta condição, serão acomodados, quando resíduos sólidos, em sacos plásticos comuns não requerendo exigências de cores. Estes tipos de resíduos poderão ser destinados a reciclagem, seguindo o modelo da coleta seletiva, ou a sua reutilização dentro própria instituição geradora.

Por fim temos os resíduos do grupo $\mathrm{E}$ que envolvem os materiais perfurocortantes cujo descarte deve ser feito em separado, no próprio local onde foi gerado e em recipientes rígidos e resistentes a exemplo do Descarpack. Por conseguinte, tais recipientes devem ser descartados quando o preenchimento atingir $2 / 3$ de sua capacidade ou nível de preenchimento ficar a 5 centímetros da abertura do recipiente sendo terminantemente proibido o seu esvaziamento ou reaproveitamento.

Como podemos observar no GRSS a apreciação dos tipos de resíduos produzidos e o levantamento da quantidade gerada figuram como uma importante necessidade a fim de garantir uma segregação e um acondicionamento eficiente e eficaz resultando numa maior redução dos riscos de contaminação do meio natural e dos seres que com ele e nele se inter-relacionam.

\section{O profissional farmacêutico e o GRSS}

É sabido que a produção de resíduos sólidos no mundo é imensa, basta uma pequena reflexão a respeito da quantidade diária de resíduos que produzimos individualmente. Estima-se que a produção mundial está avaliada entre um e dois bilhões de toneladas de resíduos por ano (Ferreira, 1995).

Os RSS são aqueles produzidos em hospitais, ambulatórios, consultórios, clínicas e similares, além de locais de grande afluxo de pessoas, e que como já mencionamos vão desde os resíduos comuns passando pelos resíduos de risco infectante ou biológico e pelos resíduos especiais.

Nos Estados Unidos a remoção e a destinação final dos RSS são referenciadas como problemas de competência dos próprios estabelecimentos e não uma atribuição dos setores de limpeza pública da cidade. Suspeita-se que por conta da tal realidade é que não se observa muitas publicações especializadas na questão de como tratar os resíduos hospitalares (Luz e Guimarães, 1972).

No Brasil cabe aos geradores de RSS e ao seu responsável legal o gerenciamento dos RSS desde a geração até a sua disposição final. Esta diretriz passou a ser efetivada após a publicação da Resolução CONAMA no 358/2005.

A riqueza de elementos químicos, físicos e radioativos nos RSS exige tratamento especializado tendo em vista o grande potencial de risco à saúde que o mesmo apresenta. Relatos epidemiológicos demonstram que algumas doenças e seus agravos possuem intima relação com os resíduos de serviço de saúde como a AIDS, o carbúnculo, a candidíase, sobretudo a Candida albicans, a cólera, a disenteria devido a enorme quantidade de agentes epidemiológicos, 
a escarlatina, a febre tifóide, a hepatite, a influenza, o Staphylococcus aureus, o tétano e a tuberculose (Brasília, 2003, p. 18-20).

Atualmente a relação entre saúde e meio ambiente está tomando conta das academias, dos grupos de discussões científicas, das instituições de ensino, das categorias ligadas a saúde e ao meio ambiente e até mesmo dentro dos mais variados grupos sociais. Dentre as diversas profissões que compõem a área da saúde damos destaque ao profissional farmacêutico por este encarnar em sua práxis o conhecimento das substâncias químicas e o saber a respeito das funções destas nos sistemas biológicos, a prática do farmacêutico também é marcada pelo direcionamento na busca da promoção e da prevenção da saúde e pela vigilância das doenças.

Diante desta realidade o farmacêutico possui uma relação intima com o GRSS, a respeito das atribuições deste no GRSS damos destaque: identificar as prováveis patologias advindas dos RSS oriundos do estabelecimento; assegurar que as informações a respeito da prévenção de infecções sejam repassadas aos profissionais da instituição; participar na elaboração de campanhas que abordem a temática dos RSS; monitorar os ambientes de trabalho onde são manipulados os RSS perigosos; participar na escolha, aprovação e avaliação da metodologia a ser utilizada no manejo e no tratamento dos RSS; atualizar o PGRSS com os devidos dados epidemiológicos; zelar pelo cumprimento da legislação sanitária e buscar manter o envolvimento e o engajamento dos profissionais da instituição na racionalização do GRSS.

As outras etapas do gerenciamento como a coleta interna nas salas de armazenamento temporário de lixo ou no expurgo e o transporte para a coleta externa estão a cargo do serviço de limpeza, ficando o destino final sob a responsabilidade do serviço de engenharia. Este, por sua vez, decidirá a forma de remoção e de tratamento cabendo ao farmacêutico, quando respon- sável pelo GRSS, a fiscalização e o contato direto com o serviço de limpeza e até mesmo com os responsáveis da destinação final dos RSS a fim de resolver qualquer problema da forma mais ágil e eficaz (Viana, 2007, p. 394).

Ao gerente de resíduos cabe responsabilidade técnica e legal de todas as etapas do gerenciamento dos resíduos de serviço de saúde, englobando tanto o Sistema de Gerenciamento Interno (SGI) quanto o Sistema de Gerenciamento Externo (SGE) (Takayanagui, 2005).

Quando um profissional é delegado a exercer a função de responsável pela elaboração e implementação do PGRSS este precisa ser detentor de um vasto conhecimento cientifico e legal básico a respeito dos RSS alem de possuir habilidade prática, pois muitas vezes não é a ausência de conhecimento que impede a prevenção de um perigo de exposição ocupacional ou de poluição do ambiente de trabalho, mas a inabilidade de sua aplicação prática. Talvez até seja pela inabilidade prática de alguns PGRSS que muitas das vezes os PGRSS são observados apenas como cumprimento de uma determinação legal. (Takayanagui, 2005).

Sobre a designação de profissional para exercer a função de responsável pela elaboração e implantação do PGRSS este se fundamentará na RDC ANVISA no 306/2004 da ANVISA, que como já foi mencionado dispõe sobre o Regulamento Técnico para o Gerenciamento de Resíduos de Serviços de Saúde.

Com um PGRSS se estabelece um importante mecanismo de gestão dos resíduos, mas também, de administração de enfermagem, pois orientam as ações dos funcionários dentro de uma instituição, as rotinas e critérios a serem estabelecidos pela Comissão de Controle de Infecção Hospitalar (CCIH), o atendimento às regulamentações dos sistemas de controle externo, de transporte e de destino final a serem adotadas em situações de emergência e acidente (Viana, 2007, p. 395).

O PGRSS não serve apenas como ferramenta de organização e de 
facilitação das etapas do GRSS, mas exerce também um trabalho de conscientização dos indivíduos que possuem ligação direta com a geração e com manuseio dos RSS (Takayanagui, 2005).

Quando um PGRSS é elaborado de forma responsável, amparado nos conhecimentos técnicos, científicos e legais e buscando alcançar como existência real os princípios da prevenção, da précaução, do poluidor pagador, do desenvolvimento sustentável, da responsabilidade solidária e, principalmente, da responsabilidade sócio-ambiental, este com toda certeza incentivará uma produção mais limpa e por conseqüência protegerá a saúde humana e do meio natural.

É fundamental que todos conheçam o que lhe é pertinente em seu orbe de ação, e gerenciar resíduos requer do profissional responsável o conhecimento técnico-cientifico, responsabilidade profissional e compromisso social, ético e ambiental.

\section{Conclusão}

Os resíduos sólidos independentes das classes a que se agrupem quer sejam eles residenciais, comerciais, públicos, resíduos de serviço de saúde, industriais, especial, entre outros, quando não tratados e destinados em locais inadequados resultará tanto em investidas lesivas contra o meio ambiente como também, contra os aspectos sociais, culturais e estéticos das sociedades.

Diante das leis em prol da proteção e conservação dos recursos do meio ambiente, cabe a nós cidadãos, conhecermos estas leis e a partir daí assumirmos a responsabilidade legal e legitima, que de nós é exigido a respeito da defesa do meio ambiente, quer sejamos pessoas física quer sejamos pessoa jurídica.

O termo responsabilidade, consiste numa obrigação de dar, fazer ou não fazer alguma coisa, de ressarcir ou reparar danos, de suportar sanções penais, exprimindo sempre a obrigação de responder por alguma coisa, tendo o particular significado da asseguração da observância de uma obrigação nela existente, ou porque se assumiu tal obrigação ou em decorrência de um fato ou ato, que ocorreu ou se praticou. A responsabilidade, então, surge como derivação de uma obrigação anterior, à qual o responsável deixou de observar. E como pondera (Monteiro, 1971, p. 148), "todo ato ilícito gera para o seu autor a obrigação de ressarcir o prejuízo causado".

No quesito dos RSS, as leis existem servindo de aparato legal e aporte para o manejo destes, entretanto, para que haja a eficácia deste especifico conjunto de leis, é extremamente necessário que cidadãos e profissionais da área de saúde, modifiquem seus conceitos e atitudes, principalmente, no que se refere ao comprometimento profissional e a proteção do meio ambiente e de seus recursos.

Por fim, apesar do presente trabalho focar a ação do farmacêutico no processo de gerenciamento dos RSS é importante ressaltar o compromisso que a ciência, a sociedade e os poderes públicos constituídos precisam ter em relação a produção, transporte $\mathrm{e}$ destinação de qualquer tipo de resíduos sólidos. É preciso compreender o papel social no tocante a conservação e preservação do meio ambiente, a busca por uma boa qualidade de vida e a inserção de fato de práticas voltadas a sustentabilidade.

\section{Conflito de interesses}

Os autores declaram não haver conflito de interesses.

\section{Referências}

ABNT - Associação Brasileira de Normas Técnicas. ABNT NBR 12807:1993. Resíduos de serviços de saúde - Terminologia. Rio de Janeiro: ABNT, 1993. 
ABNT - Associação Brasileira de Normas Técnicas. ABNT NBR 12808:1993. Resíduos de serviço de saúde - Classificação. Rio de Janeiro: ABNT, 1993.

ABNT - Associação Brasileira de Normas Técnicas. ABNT NBR 12809:1993. Manuseio de resíduos de serviços de saúde - Procedimento. Rio de Janeiro: ABNT, 1993.

ABNT - Associação Brasileira de Normas Técnicas. ABNT NBR 12810:1993. Coleta de resíduos de serviços de saúde Procedimento. Rio de Janeiro: ABNT, 1993.

ABNT - Associação Brasileira de Normas Técnicas. ABNT NBR 7500:2007. Identificação para $O$ transporte terrestre, manuseio, movimentação e armazenamento de produtos. Rio de Janeiro: ABNT, 2007.

ABNT - Associação Brasileira de Normas Técnicas. ABNT NBR 9191:2000. Sacos plásticos para acondicionamento de lixo Requisitos e métodos de ensaio. Rio de Janeiro: ABNT, 2007.

Brasil. Constituição da República Federativa do Brasil de 1988. Disponível em: <http://www.planalto.gov.br/ccivil_03/ constituicao/constituicao.htm>. Acesso em: 25 mar. 2018.

Brasil. Decreto no 16.300, de 31 de dezembro de 1923. Approva o regulamento do Departamento Nacional de Saude Publica. Disponível em: <http://www.planalto.gov. br/ccivil_03/decreto/1910-1929/D16300 impressao.htm>. Acesso em: 25 mar. 2018.

Brasil. Decreto-Lei no 4.657, de 4 de setembro de 1942. Lei de Introdução às normas do Direito Brasileiro. (Redação dada pela Lei no 12.376, de 2010). Disponível em: <http://www.planalto.gov.br/ccivil/DecretoLei/Del4657.htm>. Acesso em: 08 set. 2018.

Brasil. Lei no 8.746, de 9 de dezembro de 1993. Cria, mediante transformação, o Ministério do Meio Ambiente e da Amazônia Legal, altera a redação de dispositivos da Lei no 8.490, de 19 de novembro de 1992, e dá outras providências. Disponível em: <http://www.planalto.gov.br/ccivil_03/LEIS /1989_1994/L8746.htm>. Acesso em: 25 mar. 2018.

Brasil. Lei no 9.605, de 12 de fevereiro de 1998. Dispõe sobre as sanções penais e administrativas derivadas de condutas e atividades lesivas ao meio ambiente, e dá outras providências. Disponível em: <http://www.planalto.gov.br/ccivil_03/leis/l 9605.htm>. Acesso em: 25 mar. 2018.

Brasil. Lei no 9.782, de 9 de janeiro de 1999. Define o Sistema Nacional de Vigilância Sanitária, cria a Agência Nacional de Vigilância Sanitária, e dá outras providências. Disponível em: <http://www. planalto.gov.br/ccivil_03/leis/L9782.htm>. Acesso em: 25 mar. 2018.

Brasil. Lei no 12.305, de 2 de agosto de 2010. Institui a Política Nacional de Resíduos Sólidos; altera a Lei $\mathrm{n}$ o 9.605, de 12 de fevereiro de 1998; e dá outras providências. Disponível em: <http://www.planalto.gov. br/ccivil_03/_ato2007-2010/2010/lei/

l12305.htm>. Acesso em: 25 mar. 2018.

Brasil. Portaria MINTER no 53, de 01 de março de 1979. Disponível em: $<$ https://www.ima.al.gov.br/wpcontent/uploads/2015/03/Portaria-nb053.79.pdf>. Acesso em: 25 mar. 2018.

Brasil. Resolução CNEN no 194, de 30 de maio de 2016. Disponível em: <http://pesquisa.in.gov.br/imprensa/jsp/vis ualiza/index.jsp?jornal=515\&pagina $=1 \&$ data $=26 / 12 / 2019 \&$ totalArquivos $=149>$. Acesso em: 25 mar. 2018.

Brasil. Resolução CONAMA no 6 de 19 de setembro de 1991. Desobrigada a incineração ou qualquer outro tratamento de queima dos resíduos sólidos. Disponível em: <http://www.mma.gov.br/port/conama/res /res91/res0691.html>. Acesso em: 02 jun. 2018.

Brasil. Resolução CONAMA no 5 , de 5 de agosto de 1993. Estabelece definições, classificação e procedimentos mínimos para o gerenciamento de resíduos sólidos oriundos de serviços de saúde, portos e aeroportos, terminais ferroviários e rodoviários. Disponível em: <http://www2.mma.gov.br/ port/conama/legiabre.cfm?codlegi $=130>$. Acesso em: 25 mar. 2018

Brasil. Resolução CONAMA no 283, de 12 de julho de 2001. Dispõe sobre o tratamento e a destinação final dos resíduos dos serviços de saúde. Disponível em: <http://www2.mma.gov.br/port/conama/le giabre.cfm?codlegi=281>. Acesso em: 25 mar. 2018. 
Brasil. Resolução CONAMA no 358, de 29 de abril de 2005. Dispõe sobre o tratamento e a disposição final dos resíduos dos serviços de saúde e dá outras providências. Disponível em: <http://www2.mma.gov.br/port/ conama/legiabre.cfm?codlegi $=462>$. Acesso em: 25 mar. 2018.

Brasil. Resolução da Diretoria Colegiada no 222, de 28 de março de 2018. Regulamenta as Boas Práticas de Gerenciamento dos Resíduos de Serviços de Saúde e dá outras providências. Disponível em: <http://portal. anvisa.gov.br/documents/10181/3427425/ RDC_222_2018_.pdf/c5d3081d-b331-46268448-c9aa426ec410>. Acesso em: 30 set. 2019.

Brasil. Resolução de Diretoria Colegiada no 306, de 7 de dezembro de 2004. Dispõe sobre o Regulamento Técnico para o gerenciamento de resíduos de serviços de saúde. Disponível em: <http://www.anvisa. gov.br/divulga/eventos/biosseguranca/publi cacoes/resolucoes/RDC\%20306-2004\%20\%20ANVISA.pdf>. Acesso em: 25 mar. 2018.

Brasil. Gerenciamento dos resíduos de serviços de saúde. Brasília: Ministério da Saúde/Agência Nacional de Vigilância Sanitária, 2006.

Brasília. Manual de gestão de resíduos de saúde. Brasília: Governo do Distrito Federal, 2003.

Ferreira, J.A. Resíduos sólidos e lixo hospitalar: uma discussão ética. Caderno de Saúde Pública, v. 11, n. 2, p. 314-320, 1995.
Luz, F.X. R.; Guimarães, C. Resíduos hospitalares. Revista de Saúde Pública, v. 6, n. 4, p. 405-426, 1972.

Monteiro, W. B. Curso de Direito Civil. 7. ed. São Paulo: Saraiva, 1971.

Nalini, J. R. Ética ambiental. Campinas: Millennium, 2003.

Paraíba. Inventário de resíduos sólidos industriais do Estado da Paraíba - Brasil. João Pessoa: SUDEMA, 2004.

Takayanagui, A. M. M. Gerenciamento de resíduos de serviço de saúde. In: Arlindo Jr., P. Saneamento, saúde de ambiente: fundamentos para um desenvolvimento sustentável. Barueri: Manole, 2005. p. 324325.

Trigueiro, A. Meio ambiente no século 21. Rio de Janeiro: Sextante, 2003.

Viana, D. L. P.; Pinto, J. P.; Andrade, P. R.; Fernandes, M. G. O. A enfermagem e os resíduos dos serviços de saúde. In: Figueiredo, N. M. A. (Org.). Ensinando a cuidar em saúde pública. São Caetano do Sul: Yendis, 2007.

Wainer, A. H. Legislação ambiental brasileira: subsídios para a história do direito ambiental. Rio de Janeiro: Revista Forense, 1999.

Informação da Licença: Este é um artigo Open Access distribuído sob os termos da Licença Creative Commons Attribution, que permite uso irrestrito, distribuição e reprodução em qualquer meio, desde que a obra original seja devidamente citada. 